\title{
Diffusion of Cations Beneath Organic Coatings on Steel Substrate
}

James Pommersheim*

Tinh Nguyen

Zhouhong Zhang*

Changjian Lin**

Building and Fire Research Laboratory

Gaithersburg, Maryland 20899

*Chemical Engineering Department

Bucknell University

Lewisburg, PA 17837
**Chemistry Department

Xiamen University, Fujian

China

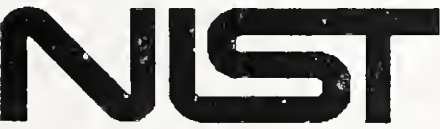

United States Department of Commerce

- "ogy Administration

QC

Institute of Standards and Technology

100

.456

\#\# 5102

1993 



\section{Diffusion of Cations Beneath Organic Coatings on Steel Substrate}

James Pommersheim

Tinh Nguyen

Zhouhong Zhang

Changjian Lin

\section{April 1993}

Building and Fire Research Laboratory

National Institute of Standards and Technology

Gaithersburg, MD 20899

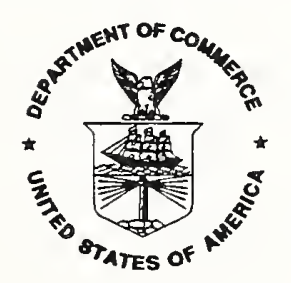

\section{U.S. Department of Commerce}

Ronald H. Brown, Secretary

National Institute of Standards and Technology

Raymond Kammer, Acting Director 



\section{Table of Contents}

\section{Abstract}

1. Introduction............................................................... 1

2. Experimental............................................................ 1

2.1. Specimen Preparation...................................................1

2.2. Cation Measurement.....................................................3

3. Conceptual Model................................................................... 3

4. Mathematical Model.............................................................4

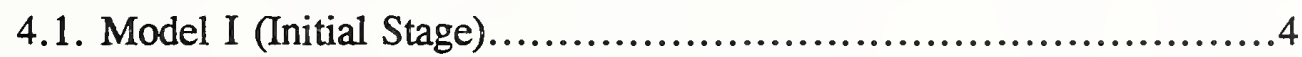

4.2. Model II (Final Stage).........................................6

5. Results and Discussion...................................................... 10

6. Summary and Conclusions...................................................... 16

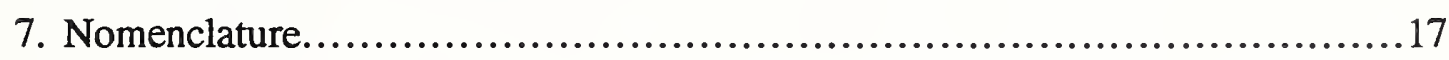

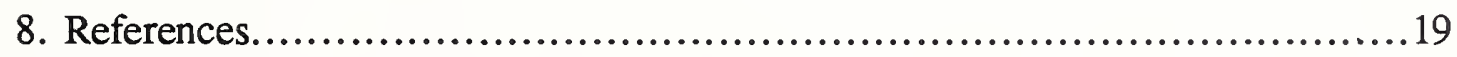

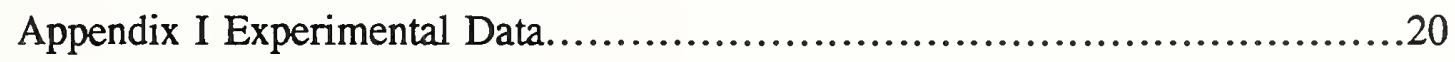

Appendix II Computer Codes.................................................21 



\begin{abstract}
Theoretical and experimental studies were carried out for the transport of cations in the channel between a polymer coating and a metal substrate from a defect in the absence of an electrical applied potential. The model consists of two stages: an initial period during which ions diffuse in the coating/metal interfacial "channel" and adsorb on the coating surface and a propagation period during which ions also diffuse into the coating. The mathematical models were solved to predict the cation concentration and flux under the coating and the relative rate of diffusion between initial and propagation periods. Model parameter values were derived from the results of an experiment conducted in a specially designed diffusion cell. The experiment measured the depletion of $\mathrm{Na}^{+}$ions in a cylindrical, central reservoir, which was placed within the perimeter of a defect scribed through the coating of an epoxy-coated steel panel. Model predictions of concentration versus time agreed well with experimental results, which showed that most of $\mathrm{Na}^{+}$ions were removed by lateral diffusion from the reservoir during the initial period. Further, the transport during the initial period was much faster than that during the propagation period. The results also indicated that during the propagation period, the rate limiting step was the lateral diffusion along the coating/metal interface rather than diffusion through the coating.
\end{abstract}





\section{Introduction}

Corrosion of metals beneath organic coatings is a problem of major importance to coating technologists. In order for corrosion to occur there must be sources of oxygen, water, and an electrolyte to transfer charge. When the corrosion occurs beneath the coating, these chemicals can be transferred by diffusion or an applied or induced potential to the corrosion site. Any of a number of processes may control the overall corrosion rate, but diffusion of chemical species is always a likely candidate to limit transport because it is inherently a slow process. Typical diffusion rates through coatings are orders of magnitude less than their unhindered values.

Migration of cations can occur by diffusion between anodic and cathodic corrosion sites at the interface between the coating and the metal. These sites may be initially close to one another, but with time they can separate and become localized. Cathodic blisters can form and eventual coating failure may result. The transport of cations such as sodium provides a mechanism to neutralize the hydroxide ions (1):

$$
\mathrm{O}_{2}+2 \mathrm{H}_{2} \mathrm{O}+4 \mathrm{e}^{-}+4 \mathrm{Na}^{+}=4\left(\mathrm{Na}^{+} \mathrm{OH}^{-}\right)
$$

In the presence of an applied or induced potential, diffusion is facilitated. It is possible to produce concentrations within cathodic blisters which are many times greater than their values in the external solution. This has been observed experimentally and predicted theoretically (2). The model of Pommersheim et al. (2) involves two periods: an initiation period and a propagation period. During the initiation period ions diffuse through the channel between the coating and the substrate. An advancing front where cations are instantaneously removed by sorption is predicted to move between the anode and the cathode. During the propagation period, cations break through into the cathodic blister where they accumulate. During both periods, the applied cathodic potential facilitates the diffusion process. A critical value of the potential was predicted below which blisters would not grow and above which they would.

In this paper the transport of cations (sodium ions) in the channel between an organic coating and a metal substrate is studied in the absence of an applied electric field. Both diffusion along the coating/metal interface and diffusion outward through the coating (in the axial direction) are considered as well as adsorption of sodium ions on the underside of the coating.

\section{Experimental}

\subsection{Specimen Preparation}

Figure 1 presents a schematic of the specimen configuration for the measurement of the diffusion of cations at the organic coating/steel interface. It consists of an organic coated substrate, an inner glass cylinder containing a solution of sodium chloride and a large, outer cylinder holding distilled water. The substrate was a SAE 1010, cold-rolled steel, and the organic coating was a commercial, two-component, room-temperature cure, pigmented epoxy 
resin. The total pigment content (by mass) in the coating was 42.5 percent. The substrate had a matte finish and surface roughness ranging from 0.9 to $1.3 \mu \mathrm{m}$. The substrate, having a dimension of $152 \times 102 \times 0.8 \mathrm{~mm}$, was cleaned by repeatedly and alternately rinsing with acetone and methanol (reagent grades), followed by dry air. The coating was applied on the substrate immediately after drying, using the draw-down technique. Excess coating was placed on one end of the substrate panel then pulled down along the length of panel using a glass rod. Masking tape strips, $5 \mathrm{~mm}$ wide, placed along the length of the panel edges were used to control the coating thickness. The coating was allowed to cure at room conditions $\left(24^{\circ} \mathrm{C}\right.$ and $45 \%$ relative humidity) for two weeks. The thickness of the coating was approximately $150 \mu \mathrm{m}$ as determined by an eddy current gage.

After curing, a disk of the coating $13 \mathrm{~mm}$ in diameter was bored to the steel substrate and removed from the center of the coated panel. A glass tube (inner cylinder), having an outside diameter of $12.5 \mathrm{~mm}$, an inner diameter of $12 \mathrm{~mm}$, and a height of $50 \mathrm{~mm}$, was placed where the coating disk was removed (Figure 1). Epoxy adhesive was used to seal the space between the glass tube and the coating. An 0.05 -mm thick gasket made of tetrafluoroethylene polymer, having an outside diameter of $13 \mathrm{~mm}$ and an inside diameter of $10 \mathrm{~mm}$, was situated at the bottom of the glass tube. This procedure ensured that the epoxy adhesive did not come into contact with the steel substrate, which could have blocked the lateral diffusion route of cations. Using a room-temperature-cure silicone adhesive, an open-ended,

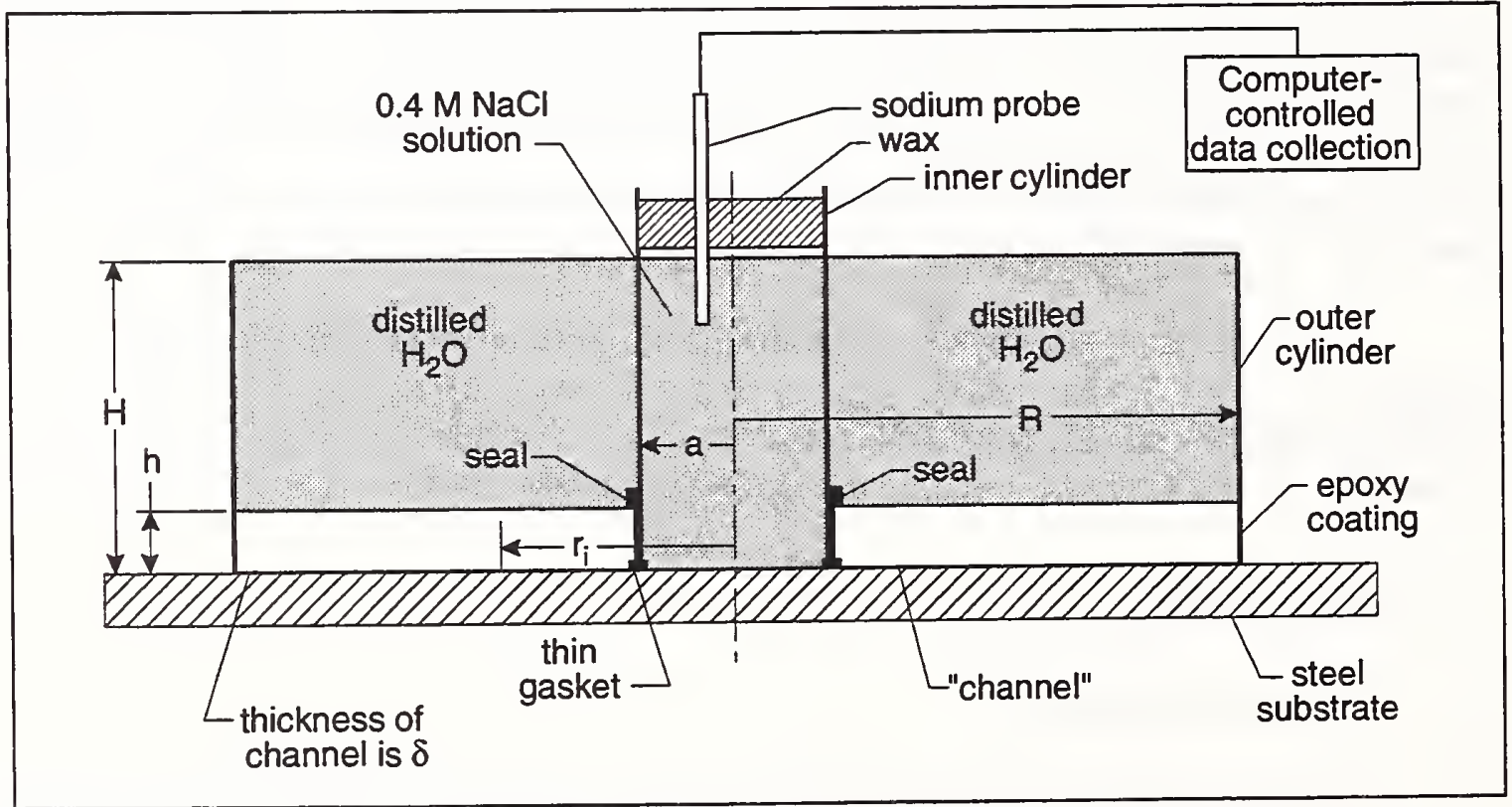

Figure 1. Specimen configuration for measuring the diffusion of cations beneath an organic coating on a substrate. 
PMMA, outer cylinder, with a height of $50 \mathrm{~mm}$ and an inner diameter of $50 \mathrm{~mm}$, was attached to the coated substrate, symmetrically around the inner cylinder. The water-filled, outer cylinder was used so that the coated specimen was completely soaked with water.

\subsection{Cation Measurement}

The diffusion of cation in the "channel" between the coating and the metal substrate was measured by following the decrease of $\mathrm{Na}^{+}$ion concentration in the inner cylinder. The concentration of $\mathrm{Na}^{+}$ions in the inner cylinder was measured using a commercial, 1-mm tip, $\mathrm{Na}^{+}$-miniselective electrode. The electrode was connected to a high-impedance $\left(>10^{14} \mathrm{ohm}\right)$ ion analyzer. The ion analyzer was programmed to record $\mathrm{Na}^{+}$ion concentrations at desired intervals. The ion-selective electrodes respond to activity rather than concentration, where activity is related to the concentration by the activity coefficient. However, because the measurement system was calibrated in terms of concentration we reported our results in terms of concentration. The $\mathrm{Na}^{+}$-selective electrode was calibrated prior to the actual measurements and its reliability was ensured by checking at the conclusion of the experiment. A preliminary experiment indicated that in order to maintain the same liquid volume in the inner cylinder throughout the measurement, the coated substrate must be saturated with water. For that reason, double-distilled water was placed in the outer cylinder 24 hours prior to filling the inner cylinder with the cation-containing solution, a $0.4 \mathrm{moles} / \mathrm{L}$ solution of $\mathrm{NaCl}$ in double-distilled water. Thus, it is expected that there was a water layer at the coating/substrate interface within the area covered by the outer cylinder prior to filling the inner cylinder with the cation solution (3).

The top of the inner cylinder was sealed with molten wax and cellophane film was used to cover the top of the outer cylinder (Figure 1). This procedure was used to minimize the evaporation of water from both cylinders. The duration of the experiment was 174 hours. There was little change in the liquid levels in both the inner and outer cylinders during this period. There was some corrosion on the bare steel area inside the inner cylinder. Further, at the end of the experiment, the coating was easily detached from the substrate, indicating that the adhesion was completely lost after the experiment. However, the metal underneath the coating was still bright and showed no evidence of corrosion. The data collected together with the specimen characteristics are presented in the Appendix I.

\section{Conceptual Model}

The sodium ions diffuse from the inner chamber (Figure 1) into the "channel" which lies between the coating and the metal substrate. There are no concentration gradients of sodium ion within the cylinders. The transport process is presumed to occur in two stages or periods. During the first period, ions diffuse through the channel to a point $\left(r_{i}\right)$ where they are rapidly removed by adsorption onto the bottom surface of the coating. This process defines a moving interface (located at $r_{i}$ ), which advances under the coating. The initiation period ends at time $\Theta_{i}$ when the interface reaches the far end of the coating $(r=R)$. During the second or last period, which begins at time $\theta_{i}$, diffusion under the coating still occurs, but this time the sink 
for the ions is diffusion of ions into the coating from the channel. Thus, in this period diffusion occurs in two directions, along the coating/metal interface (radial direction) and normal to the coating (axial direction). This process is assumed to occur by a first order process, so that where the concentration of ions in the channel is higher, more diffusion into the film will occur. During both periods ions are being removed from the solution in the inner cylinder, but during the first period ions are removed more rapidly since diffusion distances are smaller. Thus, the second stage should occur over time periods longer than the first.

Since higher concentrations of sodium are present near the entrance of the channel (at $\mathrm{r}=\mathrm{a}$ ), more transport into the coating will occur there. The amount of adsorption and diffusion into the coating will depend on the thicknesses of the channel and coating, the cell dimensions and the diffusivity of sodium ions through the channel and coating. These factors will also determine whether transport is controlled by diffusion along the coating/metal interface or through the coating.

\section{Mathematical Model}

\subsection{Model I (Initial Stage)}

During the initial stage the, A-cations (considered to be sodium ions here) are diffusing under the influence of a concentration gradient. The concentration of sodium ions is $C_{A}(t)$ at $\mathrm{r}=\mathrm{a}$ and zero at $\mathrm{r}=\mathrm{r}_{\mathrm{i}}$ where they are removed by rapid adsorption. This establishes a linear concentration gradient.

The molar flow of $\mathrm{A}, \mathrm{w}_{\mathrm{A}}$ is given by:

$$
w_{A}=-2 \pi r \delta D_{e} \frac{d C_{A}}{d r}=-2 \pi \delta D_{e} \frac{\int_{C_{a}}^{0} d C_{A}}{\int_{a}^{r_{i}} \frac{d r}{r}}=\frac{2 \pi \delta D_{e} C_{a}}{\ln \frac{r_{i}}{a}}
$$

where a is the radius of the inner cylinder, $\mathrm{r}$ is any radius, $\delta$ is the height of the channel, and $D_{e}$ is the effective diffusivity of sodium ions in the channel.

At steady state the diffusive flow must be equal to the rate at which sodium ion is adsorbed or bound to the surface:

$$
w_{A}=-\rho_{s} \frac{d r_{i}}{d t} 2 \pi r_{i}
$$


where $\rho_{s}$ is the surface molar density $\left(\mathrm{mol} / \mathrm{cm}^{2}\right)$ of sodium ions in the adsorbed layer.

Equating Eqs.(1) and (2) gives:

$$
-\rho_{s} \frac{d r_{i}}{d t}=\frac{\delta D_{e} C_{a}(t)}{r_{i} \ln \frac{r_{i}}{a}}
$$

The concentration of sodium ions $C_{a}(t)$ within the inner chamber can be found from an ion balance at $\mathrm{r}=\mathrm{a}$ :

$$
-V \frac{d C_{a}}{d t}=\left.w_{A}\right|_{r=a}=-\left.D_{e} \frac{\partial C_{A}}{\partial r}\right|_{r=a} 2 \pi a \delta
$$

where $\mathrm{V}$ is the volume of solution in the inner cylinder.

The sodium ion concentration can be found as a function of interface position by accounting for the total amount of adsorbed sodium ion:

$$
C=\frac{C_{a}}{C_{a 0}}=1-\frac{\rho_{s} \pi a^{2}}{V C_{a 0}}\left[\left(\frac{r_{i}}{a}\right)^{2}-1\right]
$$

where $\mathrm{C}_{\mathrm{ao}}$ is the initial sodium ion concentration in the inner cylinder and $\mathrm{C}$ is the dimensionless concentration.

Substituting Eq.(5) into Eq.(3):

$$
\int_{1}^{y} \frac{y \ln y d y}{(1+y)-\gamma y^{2}}=\frac{\delta D_{e} C_{a 0}}{\rho_{s} a^{2}} t=\alpha t
$$

where $y$ is the dimensionless distance $r_{i} / a$, and 


$$
\gamma=\frac{\rho_{s} \pi a^{2}}{V C_{a 0}}
$$

$\alpha$, the reciprocal of the time constant for the initial period, is given by:

$$
\alpha=\frac{\delta D_{e} C_{a 0}}{\rho_{s} a^{2}}=\frac{\pi D_{e} \delta}{V \gamma}
$$

Eq.(5) and (6) can be used together to predict the concentration of sodium ion within the inner cylinder as a function of time. The initial stage ends when $t=\theta_{i}$ at $y=R / a$. For fixed values of the parameters $\alpha$ and $\gamma$, Eq.(6) can be used to predict $\theta_{\mathrm{i}}$. As indicated by Eq.(7), $\gamma$ is a dimensionless parameter which is a measure of the amount of adsorption which can occur.

\subsection{Model II (Final Stage)}

The second or final stage begins when the first stage ends (at $t=\theta_{i}$ ). During this stage, diffusion occurs both along the coating/metal interface and into the coating. This model was developed by first making a sodium ion balance on a thin shell in the channel located at radius $\mathrm{r}$ and having width $\Delta \mathrm{r}$ :

$$
\left.2 \pi r \delta N_{r}\right|_{r}-\left.2 \pi \delta N_{r}\right|_{r+\Delta r}-\frac{2 \pi r \Delta r D_{c}\left(C_{A}-C_{A w}\right)}{h}=0
$$

where $\delta$ is the height of the channel, $N_{r}$ is the radial flux of sodium ions, $D_{c}$ is the diffusivity of sodium ions through the coating, $h$ is the coating thickness and $C_{A w}$ is the concentration of sodium ions in the outer cylinder.

In the limit as $\Delta r \rightarrow 0$ we obtain:

$$
-\frac{d\left(r N_{r}\right)}{d r}=\frac{r D_{c}}{h \delta}\left(C_{A}-C_{A w}\right)
$$

So that 


$$
\frac{1}{r} \frac{d}{d r}\left(r \frac{d C_{A}}{d r}\right)=\frac{D_{c}}{h \delta D_{e}}\left(C_{A}-C_{A w}\right)
$$

In the above formulation, several assumptions are implicit. The flux of sodium ion into the coating is taken equal to $\mathrm{D}_{\mathrm{c}}\left(\mathrm{C}_{\mathrm{A}}-\mathrm{C}_{\mathrm{Aw}}\right) / \mathrm{h}$. This formulation presumes that a linear concentration gradient of cation across the coating is rapidly established and maintained, a situation which is made more likely because the coating is thin. In addition, the diffusivities $D_{c}$ and $\mathrm{D}_{e}$ are taken constant. This is a reasonable assumption considering the uniformity of the coating and the fact that the free stream or bulk diffusivity is relatively independent of concentration for sodium chloride solutions (4). Also, since the amount of water in the outer cylinder is over ten times that of the solution in the inner cylinder (Appendix $I), C_{a w}$ will remain low as compared to $\mathrm{C}_{\mathrm{A}}$.

Eq.(11) is subject to the boundary conditions:

$$
C_{A}=C_{a}(t) \quad \text { at } r=a
$$

and

$$
\frac{\partial C_{A}}{\partial r}=0 \quad \text { at } r=R
$$

The last condition arises because there should be little or no $\mathrm{Na}^{+}$ion migrating beyond the end of the channel (at $r=R$ ) (underneath the wall of the outside cylinder). The relatively small area here $(2 \pi \delta \mathrm{R})$ insures that only a small number of ions will be transported there as compared to those that pass into the much larger area beneath the coating.

Eq.(10) and the boundary conditions can be made dimensionless by the substitutions:

$$
\Theta=\frac{C_{A}-C_{A w}}{C_{a}(t)-C_{A w}}
$$

and

$$
\xi=\frac{r}{R}
$$


leading to:

$$
\frac{1}{\xi} \frac{d}{d \xi}\left(\xi \frac{d \Theta}{d \xi}\right)=\frac{D_{c}}{h \delta D_{e}} R^{2} \Theta=m^{2} \Theta
$$

with dimensionless conditions:

$$
\Theta=1 \quad \text { at } \xi=\frac{a}{R}
$$

and

$$
\frac{d \Theta}{d \xi}=0 \quad \text { at } \quad \xi=1
$$

Alternatively, Eq.(14) can be written:

$$
\xi^{2} \theta^{\prime \prime}+\xi \theta^{\prime}-\xi^{2} m^{2} \theta=0
$$

where

$$
m^{2}=\frac{D_{c}}{D_{e}} \frac{R^{2}}{h \delta}
$$

The dimensionless parameter $\mathrm{m}$ is a measure of the relative importance of diffusion along the coating/metal interface to diffusion through the coating. If $\mathrm{m}$ is large, diffusion along the interface will control transport, while if $\mathrm{m}$ is small, diffusion through the coating will control. Because the geometric ratio $\mathrm{R}^{2} / \mathrm{h} \delta$ will, in general, be quite large for a typical coating system, if the diffusion coefficients are of comparable magnitude, diffusion along the interface is more likely to control transport. 
The solution of Eq.(15) is given in terms of modified Bessel functions:

$$
\Theta=c_{1} I_{o}(m \xi)+C_{2} K_{o}(m \xi)
$$

Applying the boundary conditions, the constants $c_{1}$ and $c_{2}$ can be found, so that:

$$
\Theta=\frac{K_{1}(m) I_{o}(m \xi)+I_{1}(m) K_{o}(m \xi)}{K_{1}(m) I_{o}\left(m \frac{a}{R}\right)+I_{1}(m) K_{o}\left(m \frac{a}{R}\right)}
$$

Eq.(18) governs the dimensionless concentration profile within the channel during the final stage.

As shown by Eq.(4), a sodium ion balance on the inner cylinder equates the depletion of sodium ions to the amount which diffuse out through the channel entrance (at $r=a$ ). The gradient $\mathrm{dC}_{\mathrm{A}} / \mathrm{dr}$ at $\mathrm{r}=\mathrm{a}$ is found by differentiating Eq.(18). Performing this operation and simplifying:

$$
-V \frac{d C_{a}}{d t}=2 \pi \frac{a \delta \eta}{h} D_{c} C_{a}
$$

where the parameter $\eta$ is given by:

$$
\eta=\frac{2 a f}{R^{2}-a^{2}} \sqrt{\frac{h D_{e} \delta}{D_{c}}}
$$

with

$$
f=\frac{I_{1}(m) K_{1}(m a / R)-K_{1}(m) I_{1}(m a / R)}{K_{1}(m) I_{o}(m a / R)+I_{1}(m) K_{o}(m a / R)}
$$

Eq.(19) is integrated to give the sodium ion concentration as a function of time: 


$$
\frac{C_{a}}{C_{a 0}}=\exp \left[-\frac{2 \pi a \delta D_{c} \eta}{V h}\left(t-\Theta_{i}\right)\right]=e^{-\alpha^{\prime}\left(t-\theta_{i}\right)}
$$

where $C^{\prime}{ }_{a 0}$ is the concentration of sodium ion at the start of the final stage $\left(t=\theta_{i}\right)$. $\alpha^{\prime}$, the reciprocal of the system time constant for model $\Pi$, is given by:

$$
\alpha^{\prime}=\frac{2 \pi a \delta D_{c} \eta}{V h}
$$

Eq. (22) predicts that the concentration will fall exponentially for times greater than $\Theta_{i}$. Together with Eqs.(5) and (6), which are valid for times less than $\theta_{\mathrm{i}}$, it governs the way that the concentration of sodium ions within the inner cylinder vary with time. Model constants can be determined by fitting experimental data to these equations.

\section{Results and Discussion}

The data given in the Appendix I for the sodium ion at different times within the inner cylinder can be used to evaluate the best values of the model constants $\alpha$ and $\gamma$ (for model I) and $\alpha^{\prime}$ (for model II). For the range of experimental data reported, $\gamma$ must lie between 0 and 0.0765 .

The initiation time $\theta_{\mathrm{i}}$ depends on both $\alpha$ and $\gamma$ since from Eq.(6):

$$
\int_{1}^{\frac{R}{a}} \frac{y \ln y d y}{(1+y)-\gamma y^{2}}=\alpha \Theta_{i}
$$

$\alpha, \alpha^{\prime}$ and $\gamma$ were found by minimizing the overall sum of squares of the deviations between the observed and predicted concentrations for both models. A numerical simulation was used to evaluate the integrals in Eq.(6) and Eq.(24). The computer programs for these operations are given in Appendix II.

The best values of the model constants for this method were found to be $\alpha=9.5 \times 10^{-3} \mathrm{~h}^{-1}, \alpha^{\prime}=5.0 \times 10^{-3} \mathrm{~h}^{-1}$, and $\gamma=0.065$. Using these values, $\theta_{\mathrm{i}}$ was evaluated as 49 hours by using Eq.(24). Figure 2 is a plot which compares the original data to that predicted by the models. A good fit is obtained for model II, while for model I, for times less than $\Theta_{i}$, the fit is not as good. This disparity may arise because of unsteady state effects associated with the initial penetration of sodium ions into the channel. Both models assume that 
diffusion occurs at quasi-steady state, so that concentrations within the channel have enough time to continually readjust to the changing concentrations within the inner cylinder. However, there may be a small initial period during which quasi-steady state is not yet established. The epoxy coating will take a short time to become acclimated to the first sodium ions which enter the channel. During this period, rapid adsorption may occur. Diffusion into the coating can also be slowed by the accumulation of sodium ions in the distilled water in the outer cylinder so that the assumption that $\mathrm{C}_{\mathrm{Aw}}=0$ will not be valid at longer times. Unfortunately, no sodium ion concentration data were collected in the outer cylinder to verify this assumption. However, even if no adsorption occurred, the highest value of $\mathrm{C}_{\mathrm{Aw}}$ could only reach $688 \mathrm{ppm}$ under the experimental conditions employed. With adsorption removing the bulk of sodium, the highest value of $\mathrm{C}_{\mathrm{Aw}}$ would fall to $107 \mathrm{ppm}$.

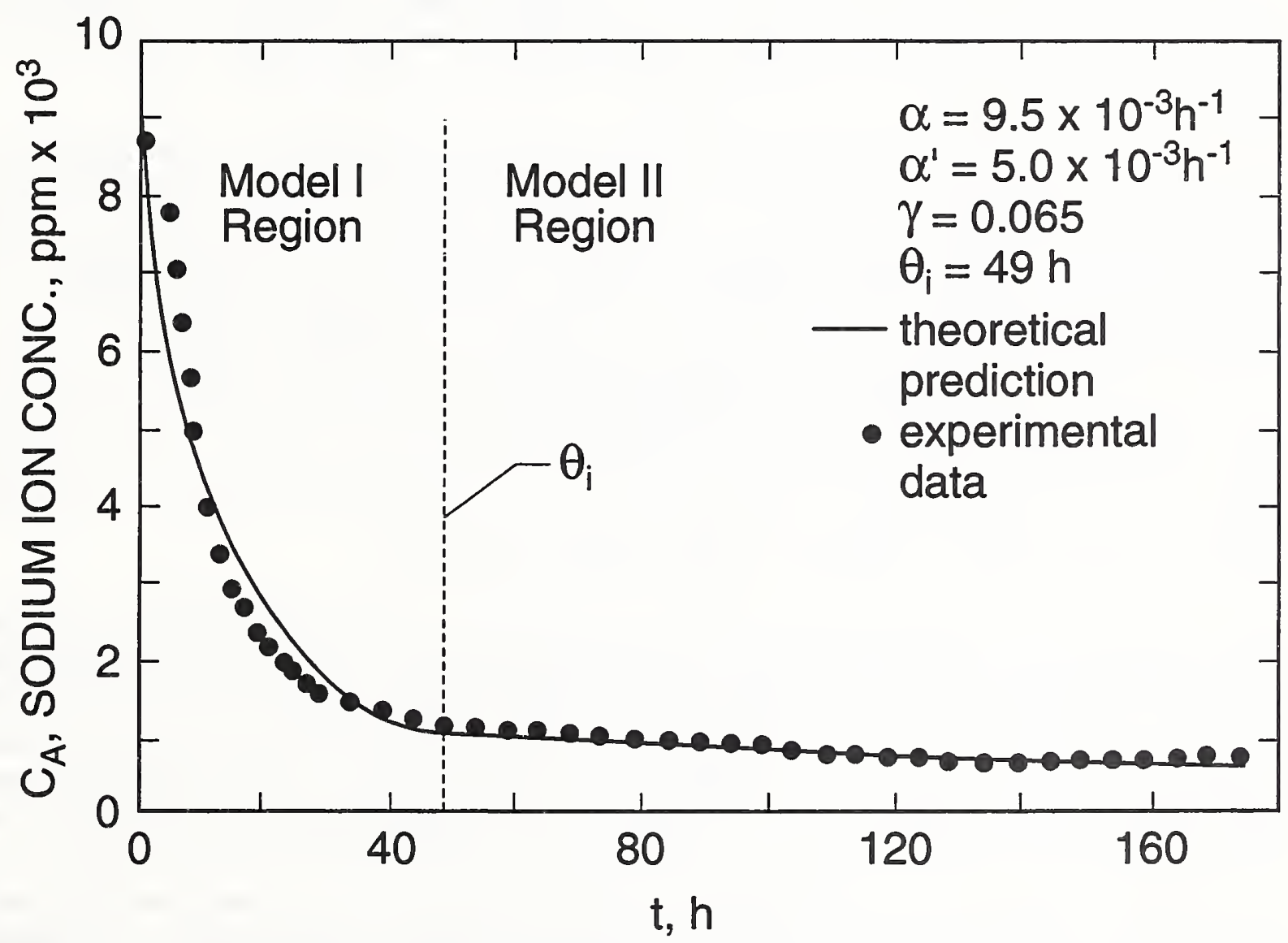

Figure 2. Comparison of predicted to experimental values of sodium ion concentration at the defect as a function of time $\left(C_{a}\right.$ vs $\left.t\right)$. 
The ratio of the constants $\alpha / \alpha^{\prime}$ is a measure of the time constant $\tau_{\mathrm{II}} / \tau_{\mathrm{I}}$, where $\tau_{\mathrm{II}}$ is the time constant for model II and $\tau_{\mathrm{I}}$ is the time constant for model I. For the experimental data obtained (Appendix I), this ratio is 1.9, indicating that the initial diffusion and adsorption of ions on the channel occurs on a time scale faster than their subsequent diffusion into the coating. The value of $\gamma\left[\left(\mathrm{R} / \mathrm{a}^{2}-1\right]\right.$ is the amount of sodium ion that can adsorb in the channel relative to the amount that is potentially available for adsorption. For the experiment conducted this is 0.85 , and from Appendix I the matching concentration occurs at about 42 hours. This indicates that the coating adsorbs all but $15 \%$ of the sodium ion available within that time. The remainder is then available to diffuse into the coating. Note that the models predict that this will occur in 49 hours.

From the best values of $\alpha$ and $\gamma$, the diffusion coefficient-channel depth product $\mathrm{D}_{\mathrm{e}} \delta$ is $1.71 \times 10^{-7} \mathrm{~cm}^{3} / \mathrm{s}$. The ease with which the epoxy coating could be detached from the steel substrate at the conclusion of the experiment suggests that $\delta$ may be large. For an average channel width of $\delta=0.1 \mathrm{~mm}$, this would give an effective lateral diffusivity of $\mathrm{D}_{\mathrm{c}}=1.71 \times 10^{-5}$ $\mathrm{cm}^{-2} / \mathrm{s}$, which is close to the free stream value for sodium chloride, $1.5 \times 10^{-5} \mathrm{~cm}^{-2} / \mathrm{s}$ (4) and three times higher than that of $\mathrm{Na}^{+}$ions through a sodium exchange membrane (5).

Figure 3 presents a plot of the parameter $\eta$ versus the modulus $\mathrm{m}$. a/R is shown as a parameter. $\eta$ is a quantitative measure of the penetration of ions. It is the ratio of the molar flow (moles/s) of ions beneath the coating to the maximum flow, which would occur if the whole underside of the coating could be exposed to solution having the external concentration $\mathrm{C}_{\mathrm{a}}$. It is a dimensionless measure of how effective the coating is in removing cations. $\eta$ values lie between 0 and 1 . Small values of $\mathrm{m}$ yield large $\eta$ values $(\sim 1)$, while at large values of $\mathrm{m}, \eta$ becomes small. With the maximum flow, there are no concentration gradients beneath the coating and the modulus $\mathrm{m}$ is small. As shown by the figure, $\eta$ is then near unity. In general, when $\mathrm{m}<0.5$ diffusion through the coating will control transport, while if $\mathrm{m}>2$ diffusion along the coating/metal interface will control. In the transition region $0.5<\mathrm{m}<2$, neither mechanism will dominate. Figure 3 delineates the three regions.

Higher values of a/R result in higher values of $\eta$ for the same modulus. $\eta$ is larger because for the same $\mathrm{R}$, diffusion distances under the coating are shorter, so that concentrations remain closer to the value in the inner solution. This is shown in Figure 4 for $m=1$ where the slope of the dimensionless concentration profiles is less at higher values of a/R. In Figure 5 higher values of $m$ result in steeper predicted profiles. The second curve from the right shows the approximate profile predicted by the model for the experimental conditions employed.

Since $\mathrm{D}_{\mathrm{c}} \delta$ and $\mathrm{a} / \mathrm{R}$ are known Eqs.(16), (20) and (21) can be solved iteratively for the values of $\mathrm{D}_{\mathrm{c}}, \mathrm{m}$ and $\eta$, yielding: $\mathrm{D}_{\mathrm{c}}=7.4 \times 10^{-8} \mathrm{~cm}^{2} / \mathrm{s}, \mathrm{m}=12.1$, and $\eta=0.055$. The outward diffusion coefficient $\left(D_{c}\right)$ value of sodium through the coating from the interface is one to three orders of magnitude higher than that reported in the literature for an epoxy coating free film $(6,7)$. One of the possible explanations for the higher diffusion coefficient of $\mathrm{Na}^{+}$obtained in this study is due the alkaline environment produced by the corrosion process at the coating/steel interface. The alkaline environment increased the internal stresses in the coatings, which 
induced macroscopic or microscopic fractures in the coating and facilitated the transport of ions.

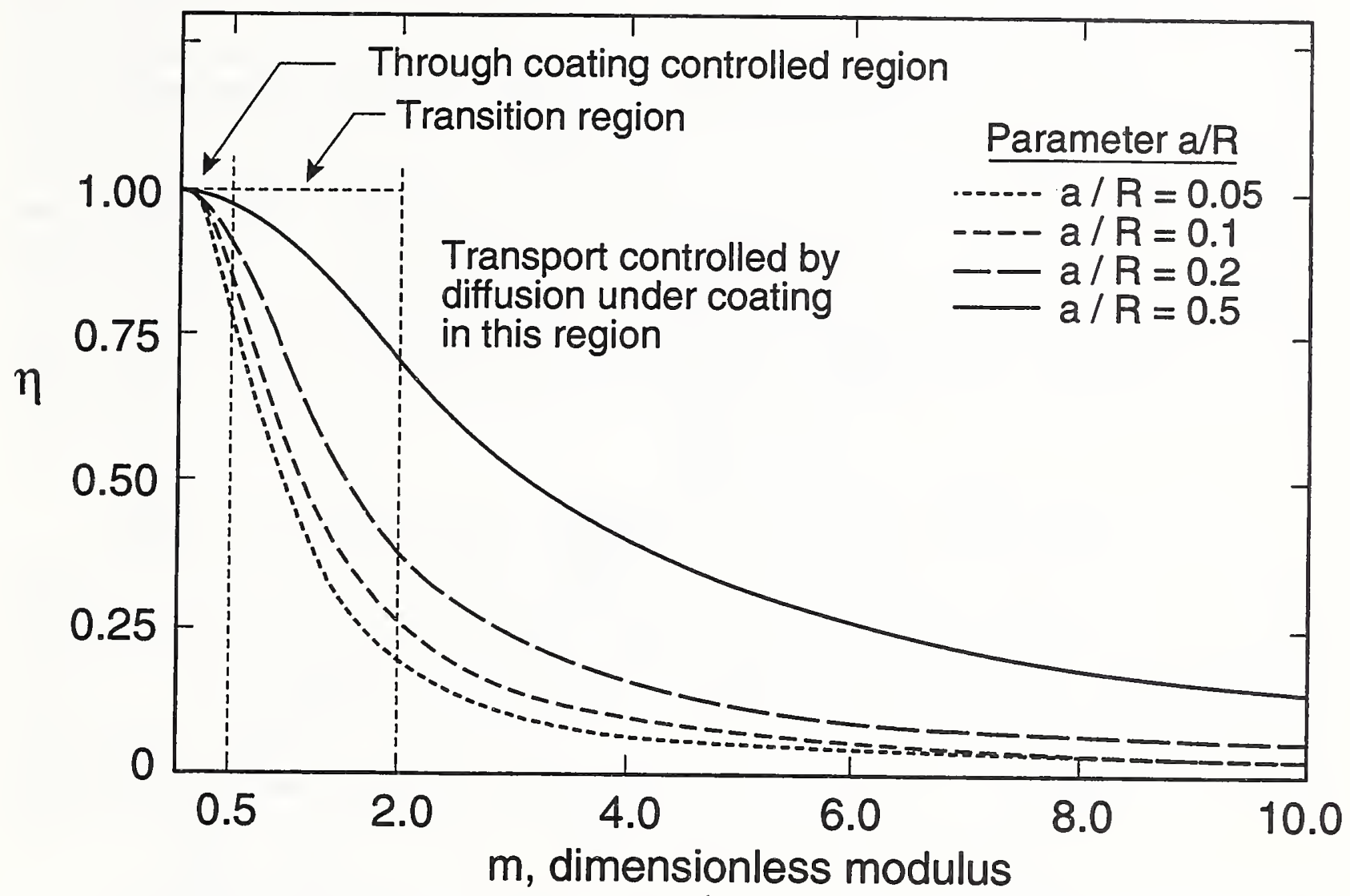

Figure 3. Plots of $\eta$ versus modulus $\mathrm{m}$. (See nomenclature section for definitions of $\eta$ and $\mathrm{m}$ )

The alkalinity is a product of the corrosion activity under the coating near the defects. This comes about because the bare metal at a large defect or a scribe mark of a polymer coated steel undergoes anodic reactions (corrosion) and the area underneath the coating surrounding the defect undergoes cathodic reactions (8-10). Sodium ions migrate along the coating/steel interface from the defect to the cathodic sites $(1,8,9)$ to neutralize the hydroxyl ions, which are produced by the cathodic reactions, forming $\mathrm{NaOH}$. Thus, the liquid at the coating/steel interface near the defects is highly alkaline. Indeed, $\mathrm{pH}$ values close to 14 have been measured at these sites (11). The alkalinity of the liquid at the coating/metal interface can cause the disbondment of a coating from a metal surface. This phenomenon is commonly known as cathodic delamination. As stated in the experimental section, we observed corrosion at the bare metal in the inner cylinder. It is likely that the cathodic delamination occurred underneath the coating surrounding the inner cylinder. This was evidenced by the complete detachment of the film from the substrate and the bright appearance of the substrate after the film was removed at the conclusion of the experiment. This may provide a partial explanation for the relatively high $\delta$ value derived from the model. 


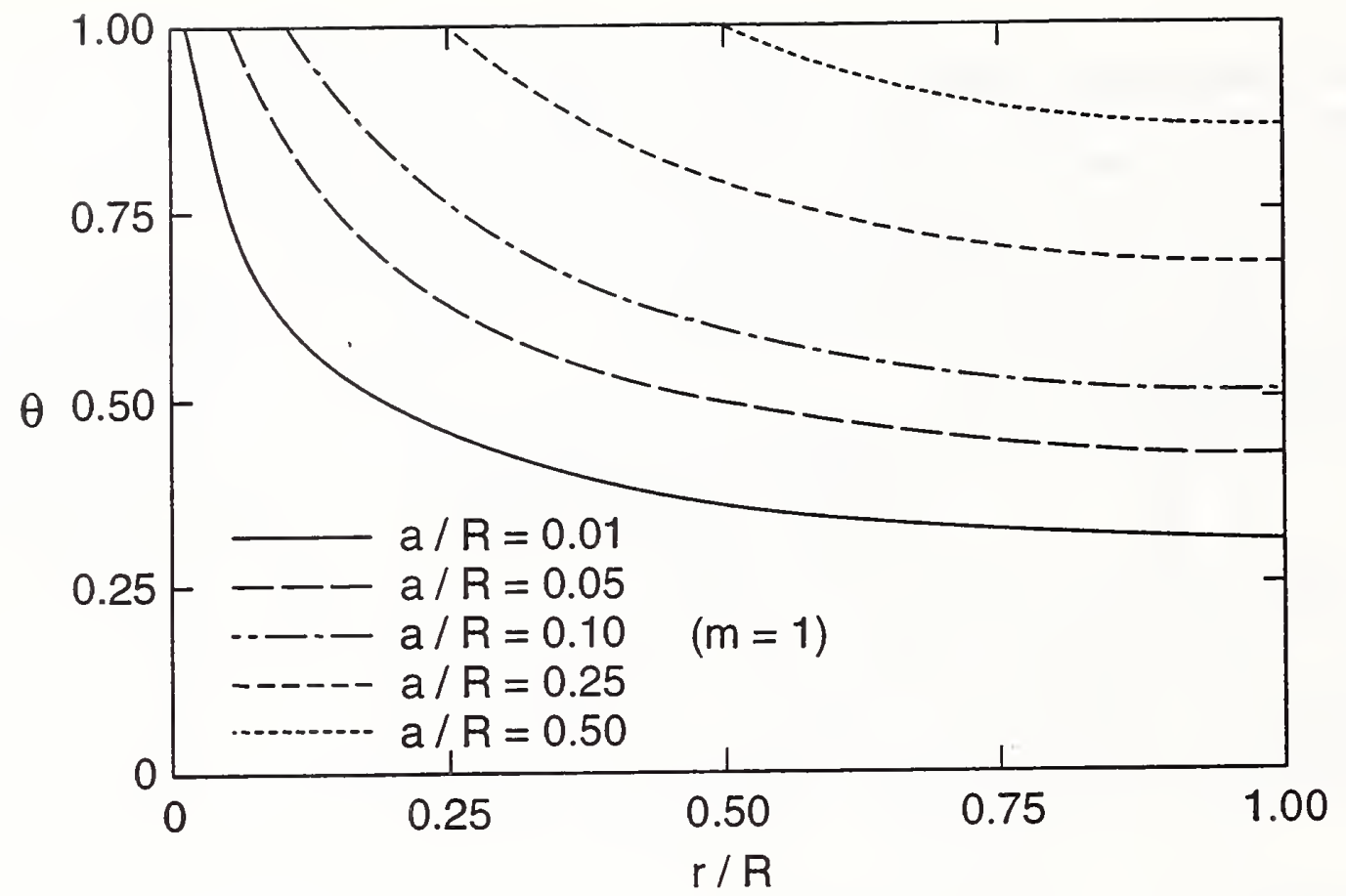

Figure 4. Plots of dimensionless concentration $\theta$ versus aspect ratio $r / R$ for $m=1$.

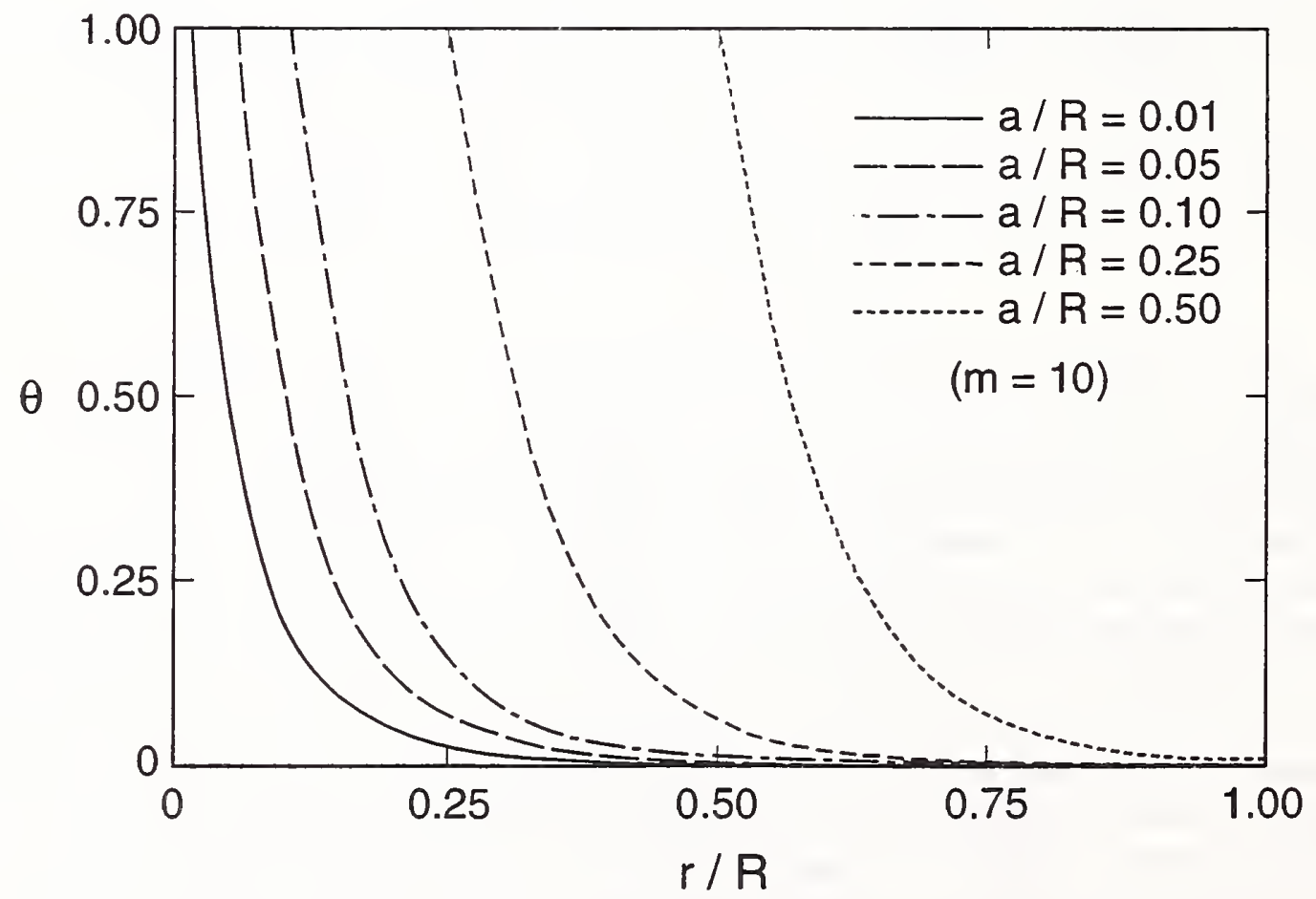

Figure 5. Plots of dimensionless concentration $\theta$ versus aspect ratio $r / R$ for $m=10$. 
The alkaline environment at the coating/steel interface may induce internal stresses in the epoxy coatings by two possible mechanisms. The first mechanism was the development of an osmotic pressure gradient between the outside water environment and the coating/steel interface. As indicated earlier, the area underneath the coating near the defect underwent cathodic reactions and this area is rich with highly hygroscopic $\mathrm{NaOH}$ corrosion products. As the result, water activity of the external solution is higher than that at the coating/steel interface, creating an osmotic pressure difference between the outside and the inside. Consequently, water flows into the coating creating a pressure that counterbalance the water in-flow. Inside the coating, the pressure generated by the swelling process produces an elastic stretching of the polymer. Swelling pressures in the range of several hundred $\mathrm{kgcm}^{-2}$ have been reported for polyamidecured epoxy films when they absorb water (7). Since the osmotic pressure gradient is a function of the water activity of the outside environment, the use of distilled water in the outer cylinder in the present study should facilitate the coating to take up maximal water and the film should stretch to its greatest extent.

Another mechanism whereby the alkali environment at the coating/steel interface may induce internal stresses in the coatings is through an increase of the fixed charges in the coating. Epoxy coatings possess fixed charges, which are produced during the curing process. The sign and concentrations of these fixed charges alter substantially when the environment in contact with the coatings change from neutral and acidic to basic (7). Since osmotic pressure is directly related to the concentration of fixed charge in the coatings (7) the alkaline environment at the coating/steel interface is expected to increase the swelling pressure in the coating. More hydrophilic polymers tend to swell more because the stronger polar or ionic-water interactions in these materials will cause a greater free energy decrease.

The existence of internal stresses in swelled polymers and their effect on transport have been documented $(12,13)$. In the presence of swelling pressure, the diffusion of penetrant has been found to be a linear function of time (instead of the square root of time as with classical diffusion). In some polymers, the internal stresses generated during diffusion were so large that the films cracked.

The relatively high value of $\mathrm{m}$ and corresponding low value of $\eta$ both indicate that diffusion along the coating/metal interface is the rate limiting step for the transport of sodium ions during the final stage. Note, however, that the ratio of the diffusivity in the channel to that in the coating $\left(D_{e} / D_{c}\right)$ is quite high (from 23 to 230 , depending on the value of $\delta$ ). Diffusion is effectively two-dimensional when most of the ions get to pass completely underneath the coating before they start to diffuse through it. In general, this would occur with a low value of $\mathrm{m}$. For the conditions employed in the present experiment, the high value of the geometric factor $\mathrm{R}^{2} / \mathrm{h} \delta$ makes $\mathrm{m}$ relatively high so that diffusion will not be two-dimensional. This can also be seen in Figure 5 where, under the experimental conditions employed, the concentration is predicted to fall towards zero only a short distance from the inner cylinder. The steep concentration gradients indicate that the principal diffusional resistance occurs in the channel under the coating. 


\section{Summary and Conclusions}

Mathematical models were developed and solved for the two stage transport of ions by diffusion beneath and through organic coatings. During the first stage transport occurred by radial diffusion in the channel between the coating and the metal with rapid adsorption on the coating underside surface. During the second stage, diffusion also occurred outward through the coating. Model parameters were obtained from an experiment conducted in a specially designed diffusion cell in which the depletion of sodium ions in a central reservoir was measured. Model predictions of concentration versus time agreed well with experimental results. Most of the sodium ions were removed during the first stage, as indicated by the relatively high value of the adsorption parameter $\gamma$. The first stage occurred more rapidly than the second, as indicated by the ratio of time constants for the two periods. High values of the diffusion modulus $\mathrm{m}$ indicated that during the second stage, cation transport was controlled by diffusion in the channel between the coating and the metal substrate rather than diffusion through the coating, even though the diffusivity of ions under the coating was much higher than that for ions through the coating. 


\section{Nomenclature}

a: radius of the inner cylinder.

$\mathrm{C}_{\mathrm{A}}$ : concentration of sodium ions in channel between the coating and the metal substrate.

$\mathrm{C}_{\mathbf{a}}:$ sodium ion concentration within the inner cylinder.

$\mathrm{C}_{\mathrm{ao}}$ : initial concentration of sodium ion.

$\mathrm{C}^{\prime}{ }_{\mathrm{aO}}$ : value of $\mathrm{C}_{\mathrm{a}}$ at $\mathrm{t}=\theta_{\mathrm{i}}$.

$\mathrm{C}_{\mathrm{Aw}}$ : concentration of sodium ions in outer cylinder.

$D_{c}$ : effective diffusivity of sodium ions through the coating from the interface.

$\mathrm{D}_{\mathrm{e}}$ : effective diffusivity of sodium ions under the coating.

f: dimensionless function defined by Eq.(21).

H: height of cylinders.

h: coating thickness.

$\mathrm{m}$ : dimensionless modulus,

$$
m=\sqrt{\frac{D_{c}}{D_{e}} \frac{R^{2}}{h \delta}}
$$

$\mathbf{N}_{\mathbf{r}}: \quad$ radial flux of sodium ions

$\mathrm{R}$ : radius of the outer cylinder.

r: radial coordinate.

$\mathrm{r}_{\mathrm{i}}$ : radius of the adsorption interface.

$\Delta r$ width of thin shell in the channel located at radius $r$.

t: time.

$\mathrm{V}$ : volume of solution in inner cylinder. 
$\mathrm{V}_{\mathrm{w}}$ : volume of water in the outer cylinder.

$\mathrm{y}$ : dimensionless radius, $\mathrm{r}_{\mathrm{i}} / \mathrm{a}$.

$\mathrm{w}_{\mathrm{A}}$ : molar flow rate of sodium ions.

$\alpha$ : reciprocal of the time constant for model I,

$$
\alpha=\frac{\delta D_{e} C_{a o}}{a^{2}}=\frac{\pi D_{e} \delta}{V \gamma}
$$

$\alpha^{\prime}:$ reciprocal of the system time constant for model II,

$$
\alpha^{\prime}=\frac{2 \pi a \delta D_{c} \eta}{V h}
$$

$\gamma$ : dimensionless adsorption parameter in model I,

$$
\gamma=\frac{\rho_{s} \pi a^{2}}{V C_{o o}}
$$

$\delta: \quad$ effective height of channel.

$\rho_{\mathrm{s}}$ : surface molar density of adsorbed layer.

$\eta: \quad$ ion penetration parameter,

$$
\eta=\frac{2 a f}{R^{2}-a^{2}} \sqrt{\frac{h D_{e} \delta}{D_{c}}}
$$

$\theta$ : dimensionless concentration, $\left(C_{A}-C_{A w}\right) /\left(C_{a}(t)-C_{A w}\right)$.

$\Theta_{\mathrm{i}}$ : time for end of first period and start of second.

$\tau_{\mathrm{I}}: \quad$ time constant for model I.

$\tau_{\text {II }}$ : time constant for model II.

$\xi: \quad$ dimensionless radius, $r / R$. 


\section{References}

1. T. Nguyen, J.B. Hubbard, and G.B. McFadden, J. Coatings Technology, 63, 43 (1990).

2. J.M. Pommersheim, T. Nguyen, Z. Zhang, C. Lin, and J.B. Hubbard, National Institute of Standards and Technology, Technical Note 1293, May, 1992.

3. T. Nguyen, E. Byrd, and C. Lin, J. Adhesion Sci. Technol., 5, 697 (1991)

4. R. Robinson and R. Stokes, "Electrolytic Solutions," 2nd ed., Academic Press, N. Y., 1959.

5. M.J. Pikal and G.E. Boyd, J. Physical Chem., 77, 2918 (1973).

6. A.L. Glass and J. Smith, J. Paint Technol., 38, 203 (1966).

7. H. Corti and R. Fernandez-Prini, Progress Organic Coatings, 10, 5 (1982).

8. W. Funke, Ind. Eng. Chem. Prod. Res. Dev., 24, 343 (1985).

9. H. Leidheiser, Jr., W. Wang, and L. Igetoft, Progress Organic Coatings, 11, 19 (1983).

10. R.A. Dickie, in "Polymeric Materials for Corrosion Control," R.A. Dickie and F.L. Floyd, Eds., Am. Chem. Soc. Symp. Series 322, Am. Chem. Soc., Washington, D.C., p. 136, 1986.

11. J.J. Ritter and J. Kruger, in "Corrosion Control by Organic Coatings," H. Leidheiser, Jr., Ed., National Assoc. Corros. Engr., Houston, TX, p. 28, 1981.

12. T. Alfrey, E.E. Gurnee and W.G. Lloyd, J. Polym. Sci., C12, 249 (1966).

13. T.K. Kwei and H.M. Zupko, J. Polym. Sci., A2, 867 (1969). 



\section{Appendix I: Experimental Data}

\section{Specimen Characteristics}

Radius of inner cylinder:

$$
\begin{aligned}
& \mathrm{a}=0.6 \mathrm{~cm} \\
& \mathrm{R}=2.25 \mathrm{~cm} \\
& \mathrm{~h}=150 \mu \mathrm{m}=1.5 \times 10^{-2} \mathrm{~cm} \\
& \mathrm{H}=3 \mathrm{~cm} \\
& \mathrm{~V}=3.39 \mathrm{ml} \\
& \mathrm{V}_{\mathrm{w}}=44.23 \mathrm{ml}
\end{aligned}
$$

Radius of outer cylinder:

Height of solutions in cylinders:

Volume of distilled water in outer cylinder:

2. Concentration $C_{a}($ ppm) of Sodium Ion within Inner Cylinder

$$
\mathrm{C}_{\mathrm{ao}}=9,000 \mathrm{ppm}
$$

\begin{tabular}{||c|c|c|c|c|c||}
\hline Time $(\mathrm{h})$ & $\mathrm{C}_{\mathrm{a}}(\mathrm{ppm})$ & Time $(\mathrm{h})$ & $\mathrm{C}_{\mathrm{a}}(\mathrm{ppm})$ & Time $(\mathrm{h})$ & $\mathrm{C}_{\mathrm{a}}(\mathrm{ppm})$ \\
\hline \hline 0 & 9000 & 29 & 1650 & 109 & 863 \\
\hline $\boldsymbol{1}$ & 8760 & 34 & 1520 & 114 & 830 \\
\hline 6 & 7800 & 49 & 1400 & 119 & 814 \\
\hline 7 & 7050 & 34 & 1310 & 129 & 863 \\
\hline 8 & 6390 & 49 & 1210 & 129 & 744 \\
\hline 9 & 5690 & 54 & 1170 & 134 & 744 \\
\hline 11 & 5000 & 59 & 1160 & 139 & 730 \\
\hline 13 & 4020 & 64 & 1150 & 144 & 718 \\
\hline 15 & 3420 & 69 & 1120 & 149 & 721 \\
\hline 17 & 2990 & 79 & 1090 & 159 & 724 \\
\hline 19 & 2410 & 79 & 1120 & 159 & 718 \\
\hline 21 & 2220 & 89 & 1000 & 169 & 721 \\
\hline 23 & 2000 & 94 & 954 & 144 & 724 \\
\hline 25 & 1870 & 99 & 929 & & \\
\hline 27 & 1730 & 104 & 880 & & \\
\hline & & & & & \\
\hline
\end{tabular}


Appendix II Computer Codes

1. Program MODELI

2. Program MODEL2

3. Program LESTSQ

4. Program FINDYI

5. Program BACKPLOT

6. Program ETAVSM

7. Program FINDDC 
PROGRAM MODELI

TITLE :

INT vs. Time Calculation

AUTHOR :

Joanne Zhang

DATE Coded:

May 6, 1991

ORGANIZATION :

Chemical Engineering Department LOCATION :

This program calculates the integral form of the mathematical model I by guessing the model constant Gamma, applying the experimental data. The Integral data as a function of time can be obtained. A subroutine in IMSL software package is employed to compute the integral form.

c

C

C:

C

C

GLOBAL CONSTANTS:

C

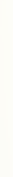

INTEGER N

PARAMETER $(\mathrm{N}=46)$

REAL CO

PARAMETER $\quad(C O=9000)$

REAL $\quad R$, RO

PARAMETER $\quad(R=4.5, \mathrm{R} 0=1.2)$

C

C

C: LOCAL VARIABLES :

C

C

INTEGER IRULE, NOUT

REAL A， ABS， B， ERRABS， ERREST， ERROR， ERRREL

REAL EXACT, F, RESULT

C

INTRINSIC ABS

EXTERNAL F, QDAG, UMACH

C

C

C: INITIALIZATION:

C

C

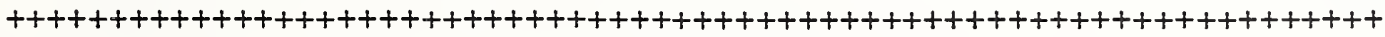

C: BODY:

C

OPEN (UNIT $=17$, FILE $=$ 'model.in')

OPEN (UNIT $=18$, FILE $=$ 'int. $2 \mathrm{~g} 076^{\prime}$ ) 
C:

GAMMAM is given a guessing value between 0.01 to 0.076 .

C

GAMA $=0.076$

PRINT*,

PRINT*, 'GAMMA $=1$, GAMA

PRINT*, $T$ T $F(Y)$

C

C:

C:

C

C

C

Integrating by using the guessing GAMMAM and IMSL

package.

DO $10 \quad I=1, N$

$\operatorname{READ}(17, *) T(I), C A(I)$

IF ( I . LE. 2I) THEN

$Y(I)=\operatorname{SQRT}((1-C A(I) / C 0) /$ GAMA +1$)$

$A=1.0$
$B=Y(I)$

ERRABS $=0.0$

ERRREL $=0.0001$

IRULE $=2$

CALL QDAG(F, A, B, ERRABS, ERRREL, IRULE, RESULT, ERREST)

C

$\operatorname{INTY}(I)=$ RESULT

$A=1.0$

$B=R / R 0$

C

ERRABS $=0.0$

ERRREL $=0.0001$

C

IRULE $=2$

CALL QDAG(F, A, B, ERRABS, ERRREL, IRULE, RESULT, ERREST)

C

C

$\operatorname{INTC}(I)=\operatorname{RESULT}$

$F Y(I)=\operatorname{INTY}(I) / \operatorname{INTC}(I)$

C

C: Data output.

c

WRITE (18, 99) T(I), FY(I)

ELSE

$\operatorname{WRITE}(*, 99) \quad T(I), \quad F Y(I)$

ENDIF

C

10 CONTINUE

C: TERMINATION:

C

99 FORMAT(IX, F5.0, 2X, F8.5)

C

END

c

c

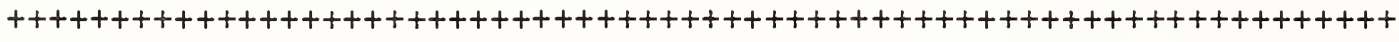

REAL FUNCTION $F(X)$

C

REAL $\quad X, G A M A$

REAL EXP

INTRINSIC EXP

C

GAMA $=0.076$

$F=X * L O G(X) /(1+G A M A-G A M A * X * * 2)$

C

RETURN

END 
PROGRAM MODEL2

TITLE :

Model II for CA/CO vs. Time

AUTHOR :

Joanne Zhang

DATE Coded:

May 5, 1991

ORGANIZATION :

LOCATION :

Chemical Engineering Department

Bucknell University

Lewisburg, PA 17837

This program calculates the ion concentration (dimensionless) as a function of time by applying the mathematical model II. The best slope of the linearized the experimental data is obtained from this program.

C: CONSTANTS:

INTEGER $\mathrm{N}$

PARAMETER $(\mathrm{N}=46)$

REAL COP

PARAMETER $($ COP $=1210)$

C

C

C: VARIABLES:

C

C

REAL $C A(N), T(N)$

REAL LN(N), TT(N)

REAL B， SUMYT， SUMTS

C

C

C: INITIALIZATION:

C

C

C

C

c

C

C:

C

C

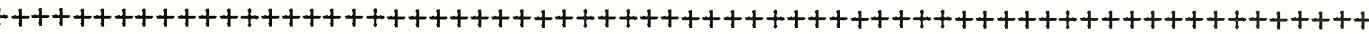

BODY :

- - -

OPEN $\left(\right.$ UNIT $=16$, FILE $=\left(\operatorname{model} 2\right.$. out2 $\left.{ }^{\prime}\right)$

OPEN $\left(\right.$ UNIT $=17$, FILE $=$ 'model. in' $\left.^{\prime}\right)$

PRINT*

PRINT*, 'T $\mathrm{TN}(\mathrm{COP} / \mathrm{CA})$

C

C

C

10 CONTINUE

Data input.

DO $10 \mathrm{I}=1, \mathrm{~N}$

$\operatorname{READ}(17, *) \mathrm{T}(\mathrm{I}), \mathrm{CA}(\mathrm{I})$

C: Calculate the best slope.

C

SUMYT $=0$

SUMTS $=0$

C 


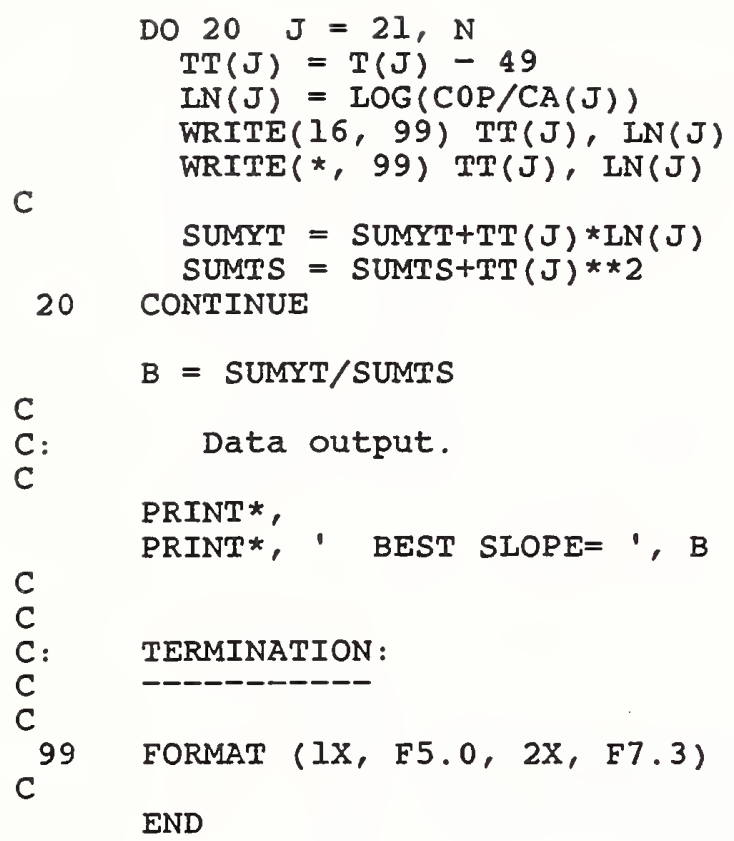


TITLE :

AUTHOR :

DATE Coded:

ORGANIZATION :

IOCATION :
Find Best GAMA by $S * * 2$

Joanne Zhang

May 16, 1991

Chemical Engineering Department Bucknell University

Lewisburg, PA 17837

C: PURPOSE:

C ------

The calculation of this program is to obtain the best value of the model constant (in model I) Gamma by minimizing the sum of the deviatioof the theoretical data and the experimental data.

CONSTANT:

C

INTEGER N

PARAMETER $(N=8)$

C: VARIABLES:

C

C

REAL GAMA(N), $\operatorname{SLOPE}(\mathrm{N})$

REAL $S(N)$

C

C

C: INITIALIZATION:

C -

C

C

C

C

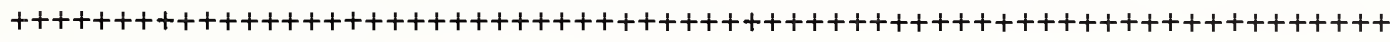

C: BODY:

C $\quad---$

C

OPEN (UNIT $=20$, FILE $=$ 'gslope.dat $2^{\prime}$ )

C

OPEN (UNIT $=11$, FILE $=$ 'gs.dat $2^{\prime}$ )

\section{PRINT*}

PRINT*, ' GAMMA $\mathrm{S} * 2$ '

C

C:

C

$$
\begin{aligned}
\text { DO } & 10 I=1, N \\
\operatorname{READ}(20, *) & \operatorname{GAMA}(I), \operatorname{SLOPE}(I)
\end{aligned}
$$

C

C

Calculate sum of the deviation, $s * * 2$ for each slope.

C

CALL SSQ(I, $\operatorname{SLOPE}(I), S(I))$

C: Data output.

C 


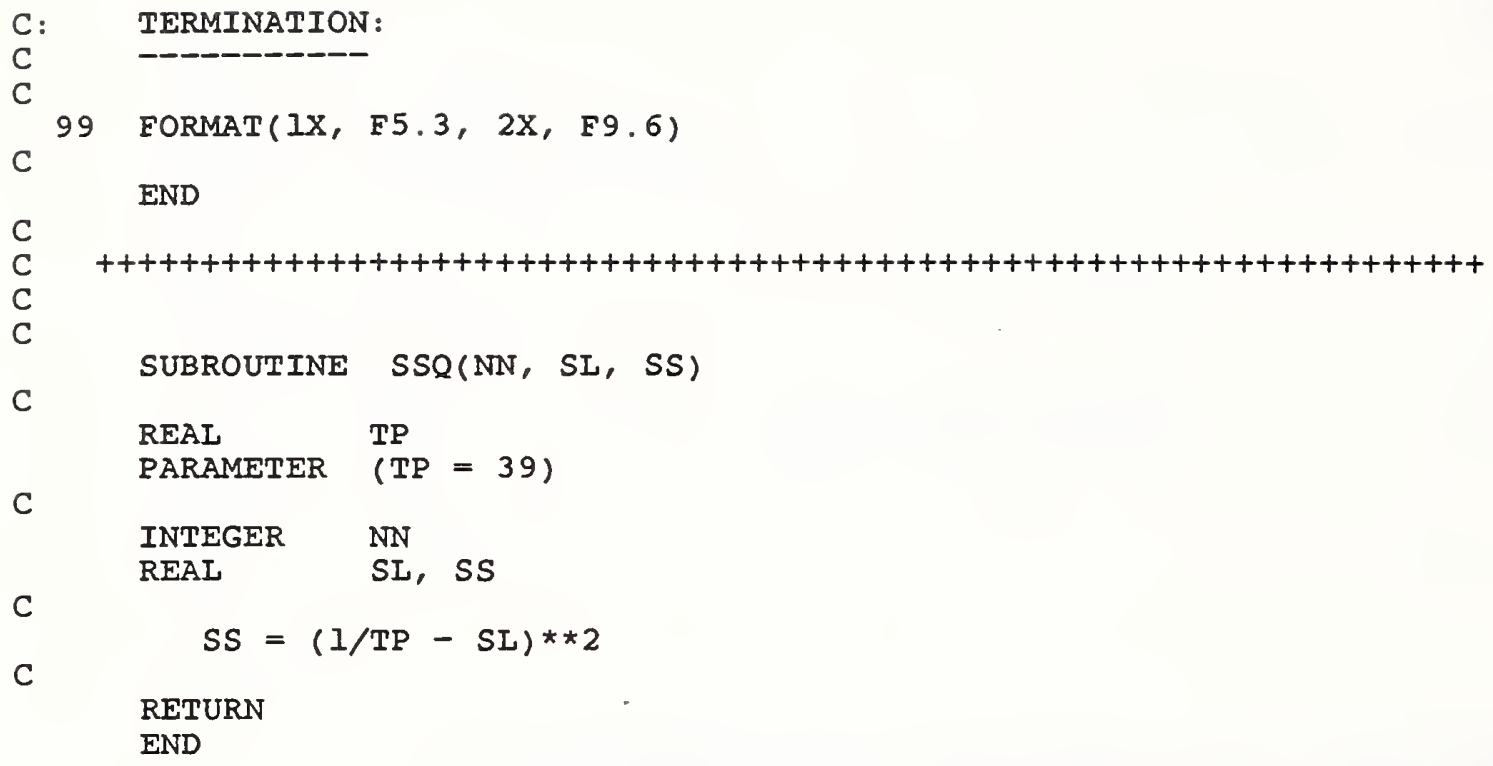


PROGRAM FINDYI

C

C

AUTHOR:

Joanne zhang

DATE Coded:

May 21, 1991

ORGANIZATION :

Chemical Engineering Department LOCATION:

\section{PURPOSE:}

This program calculates the integral form of in model $I$ as a function of time by using the best value of the model constant Gamma. A subroutine in ISML software package is applied.

C

C

$\mathrm{C}$

GLOBAL CONSTANTS :

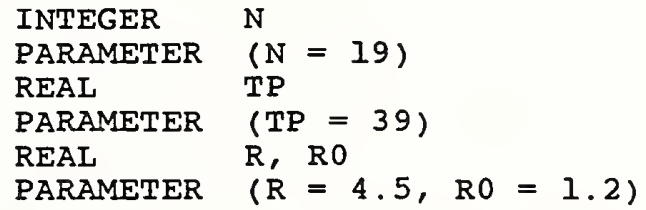

C GAMMAM is given a best value by minimizing $s * * 2$. 
GAMA $=0.07$

PRINT*,

PRINT*, $\underset{\text { PRINT* }}{\text { GAMMA }}=1$, GAMA

C: Integrating by using the best GAMMAM and IMSI

C: package.

C

$A=1.0$

C

$\mathrm{B}=\mathrm{R} / \mathrm{R} 0$

$$
\text { ERRABS }=0.0
$$

ERRREL $=0.0001$

C

IRULE $=2$

CALI QDAG(F, A, B, ERRABS, ERRREL, IRULE, RESULT, ERREST)

INTC $=$ RESULT

C

DO $10 \mathrm{I}=1, \mathrm{~N}$

$\operatorname{READ}(17, *) \mathrm{T}(\mathrm{I}), \mathrm{CA}(\mathrm{I})$

$\mathrm{RHS}(\mathrm{I})=\mathrm{INTC} * \mathrm{~T}(\mathrm{I}) / \mathrm{TP}$

C

C: $\quad$ Find $Y i$ at each $T$.

C DO $20 \mathrm{~J}=1,330$

DO $20 \mathrm{~J}=I, 330$
$\operatorname{YGUESS}(J)=(I .2+0.0 I *(J-I)) / R 0$

C

$A=1.0$

$B=\operatorname{YgUESS}(\mathrm{J})$

C

ERRABS $=0.0$

ERRREI $=0.0001$

C

IRULE $=2$

CALL QDAG(F, A, B, ERRABS, ERRREL, IRULE, RESULT, ERREST)

C

$\mathrm{C}$

$D I F=R H S(I)-R E S U L T$

IF (ABS(DIF) .IT. 0.20$)$ THEN $\mathrm{YI}(\mathrm{I})=\mathrm{YGUESS}(\mathrm{J})$

ELSE

ENDIF

C

20 CONTINUE

C

C: Data output.

C

50 WRITE $(28,99) T(I), Y I(I)$

WRITE(*, 99) T(I), YI(I)

C

10 CONTINUE

C

C: TERMINATION:

C - - - - - - -

C

99 FORMAT (1X, F5.0, 2X, F8.5)

C

END

C

C

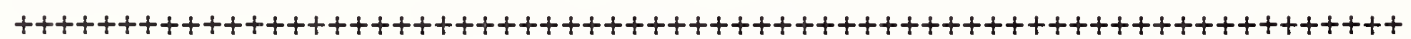

C

C

REAL

FUNCTION $F(X)$

REAI $X$, GAMA

REAL EXP

C

INTRINSIC

EXP

GAMA $=0.07$ 


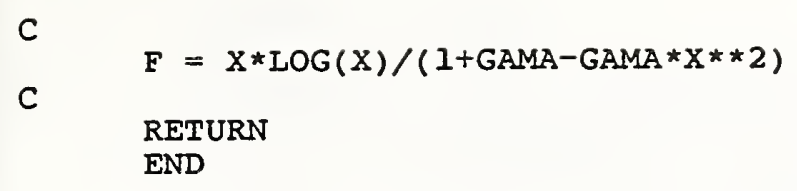


$$
\text { C }
$$

C

: PURPOSE :

C

C

C: CONSTANTS :

C

C

C

C: VARIABLES :

$\mathrm{C}$

C

C: INITIALIZATION :

C

C

C

C

C

C

C

C:$$
\text { C }
$$

Data input.

DO $100 I=1,19$

$\operatorname{READ}(36, \star) \mathrm{T}(I), \mathrm{YI}(I)$

CONTINUE

DO $10 I=1, N$
Backplot for Data set

Joanne Zhang

May 22, 1991

Chemical Engineering Department * Bucknell University Lewisburg, PA 17837
This program calculates the theoretical data points by applying model I and model $I$. The best value of model constant Gamma and the best value of the slope are used. The set of data will be employed to make a backplot of the experimental data.

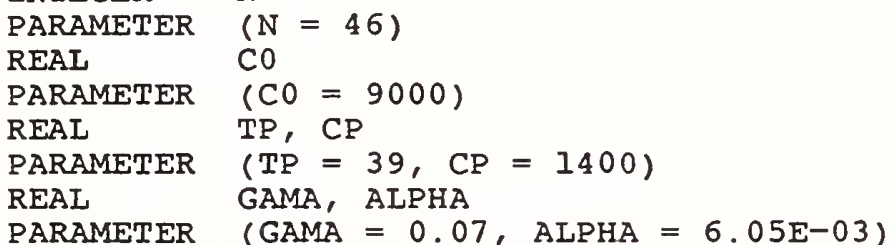




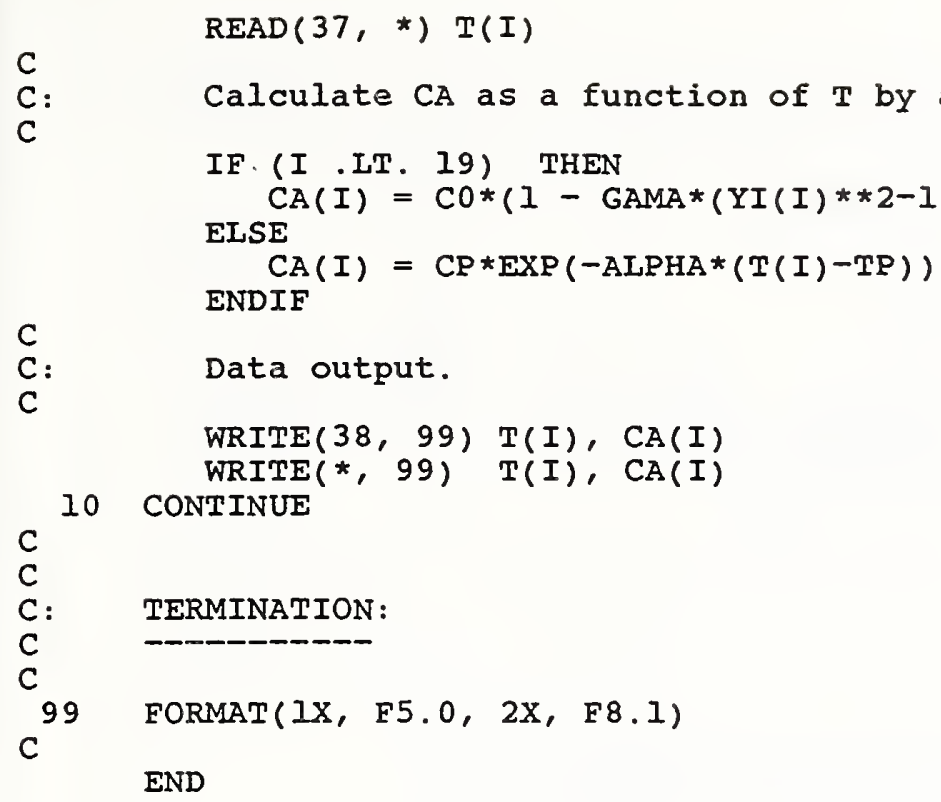

C

C:

C

C.

C: Data output.

C

WRITE (38, 99) T(I), CA(I)

10 CONTINUE

IF. (I .LT. 19) THEN

ELSE

$\mathrm{CA}(I)=C P * \operatorname{EXP}(-\operatorname{ALPHA} *(T(I)-T P))$

c

C: TERMINATION :

C

99 FORMAT(IX, F5.0, 2X, F8.1)

END 
PROGRAM ETAVSM

TITLE :

AUTHOR :

DATE Coded:

ORGANIZATION :

LOCATION :
Eta vs. M Calculation

Joanne Zhang

July 15, 1991

Chemical Engineering Department Bucknell University

Lewisburg, PA 17837

PURPOSE:

This program calculates the the effectiveness factor Eta and as a function of parameter $m$ with the ratio of $a / R$ as $a$ parameter. Bessel's function subroutines in the IMSI software package are uesd in this program.

CONSTANTS :

C : CONSTANTs:

REAL AR

PARAMETER $\quad(A R=0.5)$

C

INTEGER N

PARAMETER $\quad(N=101)$

C

C: VARIABLES :

C D-- - -

C

C

REAL $\quad E E(N), M(N)$

REAL MM

REAI $\quad F(N)$

REAL BSI0, BSII, BSKO, BSKI

EXTERNAI BSI0, BSII, BSK0, BSKI

C

C

C: INITIALIZATION :

C

C

C

C

C

C

C:

C

C

$++++++++++++++++++++++++++++++++++++++++++++++++++++++++++++++++++$ BODY :

$$
\text { OPEN (UNIT }=22, \text { FILE }=\text { 'em. } \mathrm{k} 5^{\prime} \text { ) }
$$

$\mathrm{MM}=0.1$

DO $10 \quad I=1, N$

IF (I .EQ. 1) THEN

$$
\underset{\operatorname{ELSE}}{M(I)}=0.001
$$

ENDIE

$M(I)=(I-I) * M M$

C

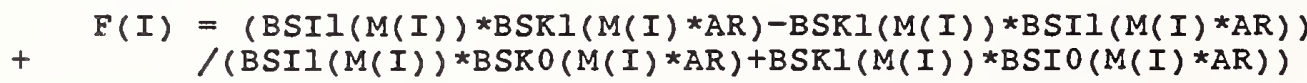


10 CONTINUE

$\underset{\operatorname{CONTINUE}}{\operatorname{EE}(I)}=2 \star F(I) * \mathrm{AR} /(M(I) *(I-\mathrm{AR} * * 2))$

Data output.

C:

PRINT*,

$c$

PRINT*,' M EE '

DO $30 I=1, N$

$\operatorname{WRITE}(*, 55) \quad \mathrm{M}(I), \mathrm{EE}(I)$

30 CONTINUE

WRITE $(22,55) \quad M(I), \operatorname{EE}(I)$

C

C

C: TERMINATION:

C

C

55 FORMAT(2X, F7.3, 2X, F7.5)

C

END 
PROGRAM FINDC

C
$C$
$C$
$C$
$C$
$C$
$C$
$C$
$C$
$C$
$C$
$C$
$C$
$C$
$C$
$C$
$C$
$C$
$C$
$C$
$C$
$C$
$C$
$C$
$C$
$C$
$C$
$C$
$C$
$C$
$C$
$C$
$C$
$C$

* TITLE :

AUTHOR :

DATE Coded:

ORGANIZATION :

LOCAT ION :
M, Eta, Dc Calculation

Joanne zhang

July 15, 1991

Chemical Engineering Department Bucknell University

Lewisburg, PA 17837

: PURPOSE:

This program calculates the prarameter m in function by guessing $m$ and solving equations(21), (22), and (30) simultaneously to find the best value of $\mathrm{m}$. The values of $f$ and Dc can also be obtained. Four special function in the IMSL software package are employed in this program.

C

CONSTANTS :

REAL GAMMA

PARAMETER (GAMMA $=0.06$ )

REAL ALPHA

PARAMETER (ALPHA $=9.5 \mathrm{E}-03$ )

REAL ALPHAP

PARAMETER (ALPHAP $=5.0 \mathrm{E}-03$ )

REAL AR

PARAMETER (AR $=0.267$ )

REAL A, R

PARAMETER $(A=0.6, R=2.25)$

REAL $V, \mathrm{H}$

PARAMETER $(\mathrm{V}=3.39, \mathrm{H}=1.5 \mathrm{E}-02)$

REAL PI

PARAMETER ( $P I=3.14$ )

C

C: VARIABLES

C D-D-C-D

C

REAL M, ETA, DC

REAL DEDEL, CM, F

REAL MG，FG，DCG

C

REAL TOL

$\begin{array}{ll}\text { REAL } & \text { BSI0, BSII, BSR0, BSKI } \\ \text { EXTERNAL } & \text { BSI0, BSII, BSK0, BSKI }\end{array}$

C

C

C: INITIALIZATION:

C -

C

C

C

C

$++++++++++++++++++++++++++++++++++++++++++++++++++++++++++++++++++$

C: BODY:

C - -

C: Calculate DEDEL by using ALPHA, V, and GAMMA. 


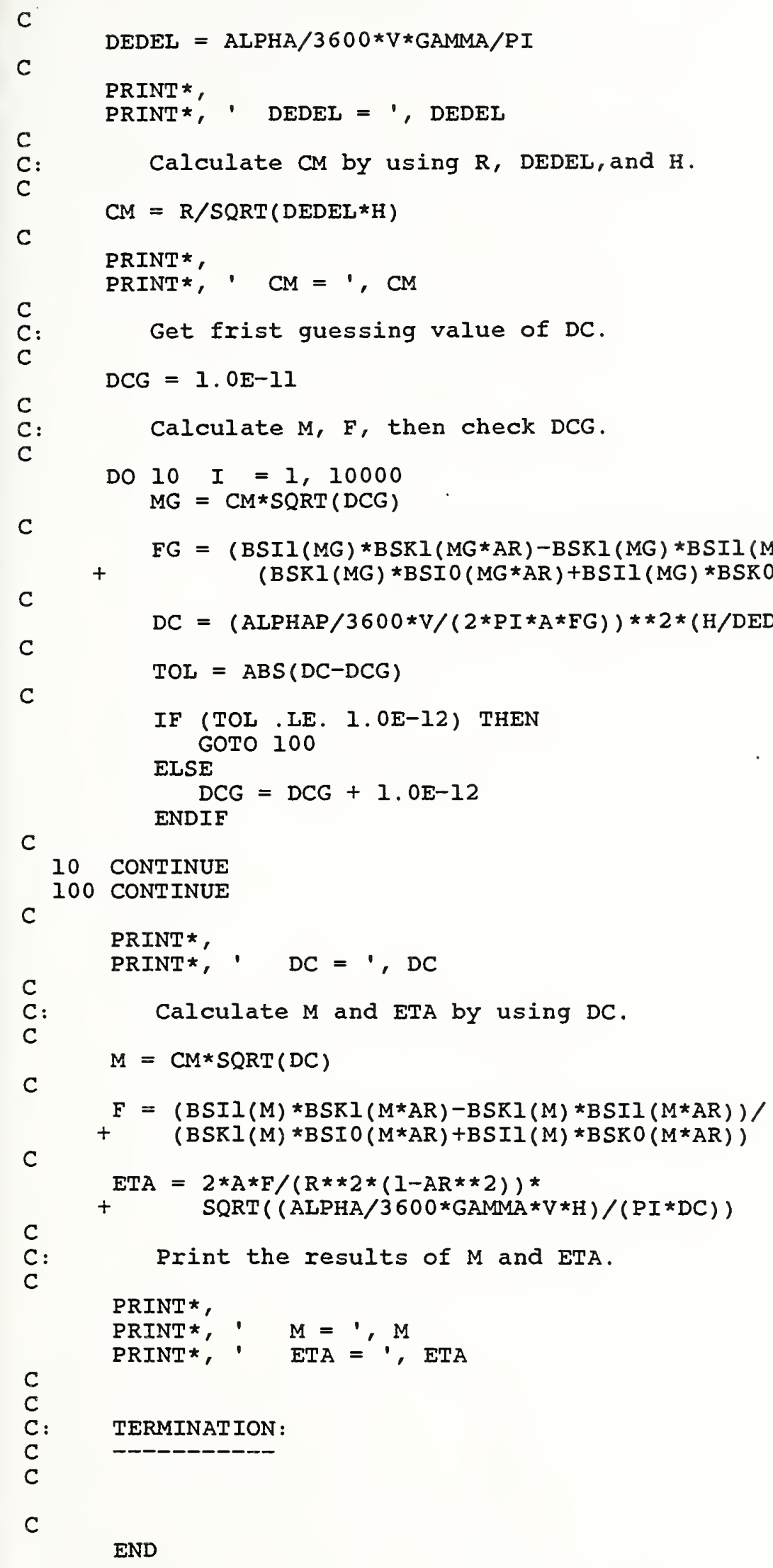




